\title{
Maximum-power-point tracking control of solar heating system
}

\author{
Bin-Juine Huang*, Wei-Zhe Ton, Chen-Chun Wu, Hua-Wei Ko, Hsien-Shun Chang, \\ Rue-Her Yen, Jiunn-Cherng Wang
}

New Energy Center, Department of Mechanical Engineering, National Taiwan University, Taipei, Taiwan

Received 17 February 2012; received in revised form 16 July 2012; accepted 30 August 2012

Communicated by: Associate Editor Yanjun Dai

\begin{abstract}
The present study developed a maximum-power point tracking control (MPPT) technology for solar heating system to minimize the pumping power consumption at an optimal heat collection. The net solar energy gain $Q_{n e t}\left(=Q_{s}-W_{p} / \eta_{e}\right)$ was experimentally found to be the cost function for MPPT with maximum point. The feedback tracking control system was developed to track the optimal $Q_{n e t}$ (denoted $Q_{\max }$ ). A tracking filter which was derived from the thermal analytical model of the solar heating system was used to determine the instantaneous tracking target $Q_{\max }(t)$. The system transfer-function model of solar heating system was also derived experimentally using a step response test and used in the design of tracking feedback control system. The PI controller was designed for a tracking target $Q_{\max }(t)$ with a quadratic time function. The MPPT control system was implemented using a microprocessor-based controller and the test results show good tracking performance with small tracking errors. It is seen that the average mass flow rate for the specific test periods in five different days is between 18.1 and $22.9 \mathrm{~kg} / \mathrm{min}$ with average pumping power between 77 and $140 \mathrm{~W}$, which is greatly reduced as compared to the standard flow rate at $31 \mathrm{~kg} / \mathrm{min}$ and pumping power $450 \mathrm{~W}$ which is based on the flow rate $0.02 \mathrm{~kg} / \mathrm{s} \mathrm{m}$ defined in the ANSI/ASHRAE 93-1986 Standard and the total collector area $25.9 \mathrm{~m}^{2}$. The average net solar heat collected $Q_{n e t}$ is between 8.62 and $14.1 \mathrm{~kW}$ depending on weather condition. The MPPT control of solar heating system has been verified to be able to minimize the pumping energy consumption with optimal solar heat collection.
\end{abstract}

(c) 2012 Elsevier Ltd. All rights reserved.

Keywords: Solar system; Solar process heat; Solar thermal; Solar heating; Solar collector; Solar control

\section{Introduction}

Forced-circulation solar heating system has been widely used in industrial and domestic heating process. The solar heating system consists of multiple banks of solar collectors and uses a pump to circulate the working fluid (water, glycol solution, or heating medium) through the collectors. The electric pumping energy is consumed. The solar heat absorbed increases with increasing flow rate as well as pumping power. Although a careful piping design to reduce the pressure loss in pipelines is important, the opti-

\footnotetext{
* Corresponding author. Tel.: +8862 23634790; fax: +886223640549. E-mail address: bjhuang@seed.net.tw (B.-J. Huang).
}

mal control of pumping flow rate can also effectively reduce the pumping power.

A lot of solar heating systems were usually designed to operate at a flow rate given by the standard flow rate used in the collector standard test, $0.02 \mathrm{~kg} \mathrm{~m}^{-2} \mathrm{~s}^{-1}$, which may be over-estimated and causes larger pumping power consumption. The purpose of the flow rate control is to reduce the pumping power but without changing the solar heat collection.

Many researchers intended to develop an optimal control technique to reduce the pumping power at optimal solar heat collection (Kovarik and Lesse, 1976; De Winter, 1992; Badescu, 2007; Bejan and Schultz, 1982) such as using exergy concept (Badescu, 2007) or system optimization method (Bejan and Schultz, 1982) The control 


\begin{tabular}{|c|c|}
\hline \multicolumn{2}{|c|}{ Nomenclature } \\
\hline$A_{c}$ & absorber area of solar heating system, $\mathrm{m}^{2}$ \\
\hline$C_{p}$ & specific heat of working fluid, $\mathrm{kJ} / \mathrm{kg}{ }^{\circ} \mathrm{C}$ \\
\hline$F_{i}$ & $\begin{array}{l}\text { cost function at time instant } i \text { for tracking con- } \\
\text { trol }\end{array}$ \\
\hline$F_{R}(\tau \alpha)$ & $\begin{array}{l}\text { flow transmittance-absorptance coefficient of } \\
\text { solar collector, dimensionless }\end{array}$ \\
\hline $\begin{array}{l}F_{R} U_{L} \\
I_{T}\end{array}$ & $\begin{array}{l}\text { heat loss coefficient of solar collector, } \mathrm{W} / \mathrm{m}^{2} \mathrm{~K} \\
\text { solar radiation intensity on collector slope, } \mathrm{W} / \\
\mathrm{m}^{2}\end{array}$ \\
\hline$K_{p}$ & parameter of PI controller \\
\hline$\dot{m}$ & mass flow rate through collector, $\mathrm{kg} \mathrm{s}^{-1}$ \\
\hline$Q_{\text {net }}$ & net energy gain, $\mathrm{kW}$ \\
\hline$Q_{\max }$ & $\operatorname{maximum} Q_{n e t}, \mathrm{~kW}$ \\
\hline$Q_{s}$ & total heat energy collected $=\dot{m} C_{p}\left(T_{e}-T_{i}\right), \mathrm{kW}$ \\
\hline$q_{s}$ & $\begin{array}{l}\text { total heat energy collected per unit area of solar } \\
\text { absorber }=Q_{s} / A_{c}, \mathrm{~kW} / \mathrm{m}^{2}\end{array}$ \\
\hline$s$ & Laplace variable \\
\hline$T_{a}$ & ambient temperature, ${ }^{\circ} \mathrm{C}$ \\
\hline
\end{tabular}

$T_{e} \quad$ outlet temperature of collector, ${ }^{\circ} \mathrm{C}$

$T_{i} \quad$ inlet temperature of collector, ${ }^{\circ} \mathrm{C}$

$T_{I} \quad$ parameter of PI controller

$W_{p} \quad$ pumping power consumption, $\mathrm{W}$

$\eta_{e} \quad$ efficiency of electric grid, dimensionless

$\tau_{s} \quad$ time constant of solar heating system, $\mathrm{s}$

$\eta_{s} \quad$ energy conversion efficiency of solar collector, dimensionless

$\widetilde{I}_{T}(t) \quad$ perturbed value of $I_{T}$

$\bar{I}_{T} \quad$ steady state of $I_{T}$

$\tilde{q}_{s}(t) \quad$ perturbed value of $q_{s}$

$\bar{q}_{s} \quad$ steady state of $q_{s}$

$\tilde{\dot{m}}(t) \quad$ perturbed value of $\dot{m}$

$\dot{\dot{m}} \quad$ steady state of $\dot{m}$

$\widetilde{T}_{a}(t) \quad$ perturbed value of $T_{a}$

$\bar{T}_{i} \quad$ steady state of $T_{i}$

$\widetilde{T}_{i}(t) \quad$ perturbed value of $T_{i}$ algorithms however were very complicated and not easy to be implemented. In addition, no tracking feedback control scheme has ever been applied to assure the optimal performance under variable solar radiation. In the present study, we intend to develop the technology of maximum-powerpoint tracking control (MPPT), similar to MPPT of solar PV system, but for solar heating system.

\section{Design of solar heating system}

A solar heating system using flow-through vacuum-tube solar collectors was designed and installed for experiment. The solar heating system, as shown in Fig. 1, consists of 24 sets of vacuum-tube solar collectors with $26 \mathrm{~m}^{2}$ total absorber area. The piping is designed with eight collectors in series and three in parallel connections, for total 24 collectors. The reverse-return piping design is adopted to maintain a uniform flow through the collector banks. An inverter for

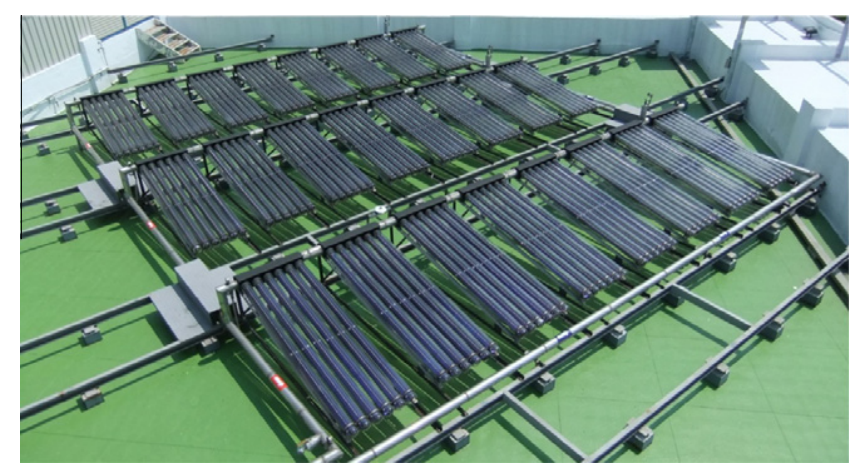

Fig. 1. Solar heating system used in the present study. rotational speed control of the circulation pump was installed and a PC-based control system was developed for the control of the circulation pump. The system configuration is shown in Fig. 2, where $T_{e}$ is the water temperature at solar collector outlet and $T_{i}$ is the water temperature at the bottom of the buffer tank which is close to the inlet temperature.

Most of solar heating systems were designed at the flow rate $0.02 \mathrm{~kg} \mathrm{~m}^{-2} \mathrm{~s}^{-1}$ used in the standard test of solar collector. That is, the total flow rate for the present solar system will be rated at $31 \mathrm{~kg} / \mathrm{min}$ with $450 \mathrm{~W}$ pumping power. This may be too high and can be reduced without affecting the energy collection.

\section{Determination of cost function for optimal tracking control}

In order to develop an optimal control for water pump, the cost function must be found first. The total solar heat absorbed by the solar collector $Q_{s}$ increases with increasing flow rate. However, the associated pumping power may become unreasonably high. After certain range of high flow rate, the increase of flow rate no longer increases the total solar heat collection $Q_{s}$. The net energy gain $Q_{n e t}$ can be defined as the total heat energy collected $Q_{s}$ minus the electric pumping energy $W_{p}$ which is converted into the primary heat energy:

$Q_{n e t}=Q_{s}-\frac{W_{p}}{\eta_{e}}$

where $\eta_{e}$ is the primary energy efficiency of the electrical grid (0.365 in Taiwan), $Q_{s}=\dot{m} C_{p}\left(T_{e}-T_{i}\right), T_{i}$ and $T_{e}$ are 


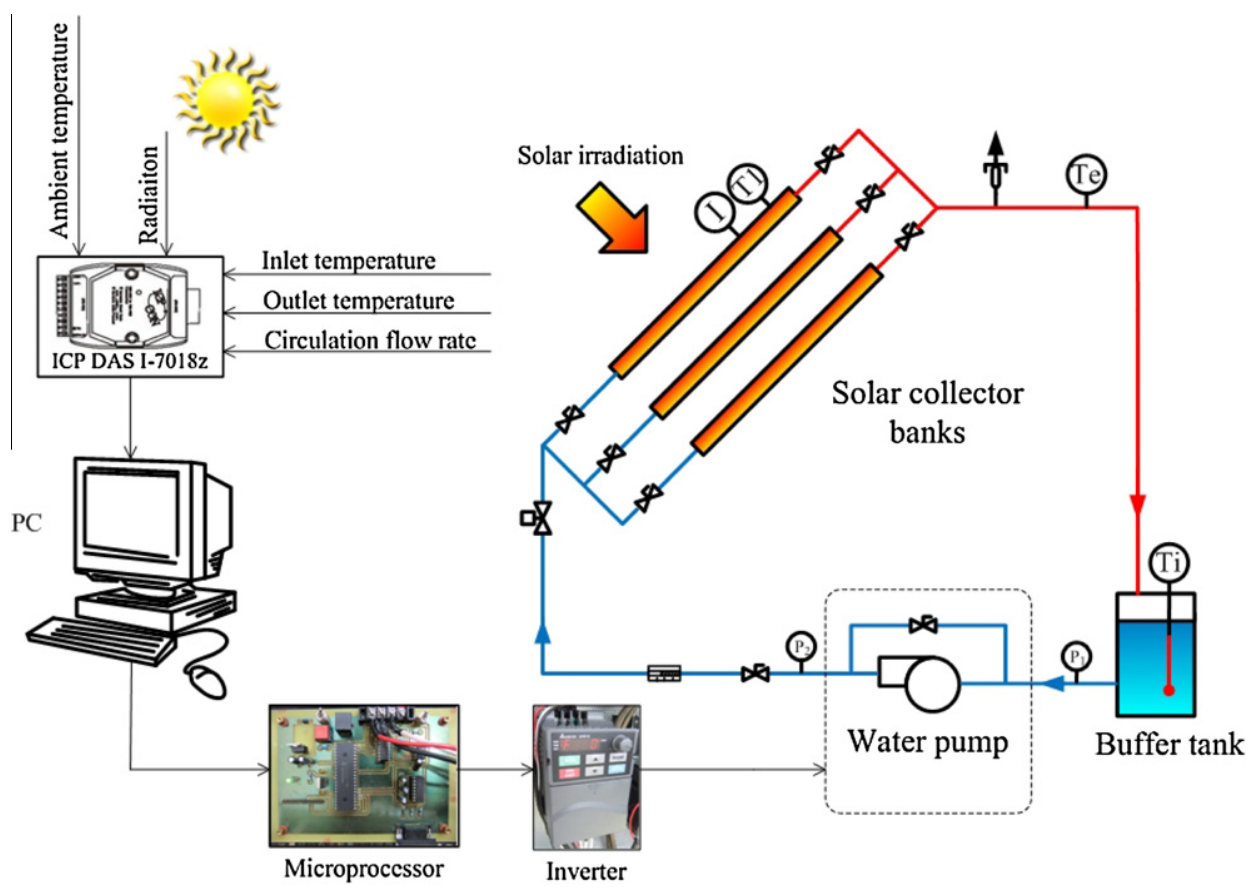

Fig. 2. Schematic diagram of control system design of solar heating system.

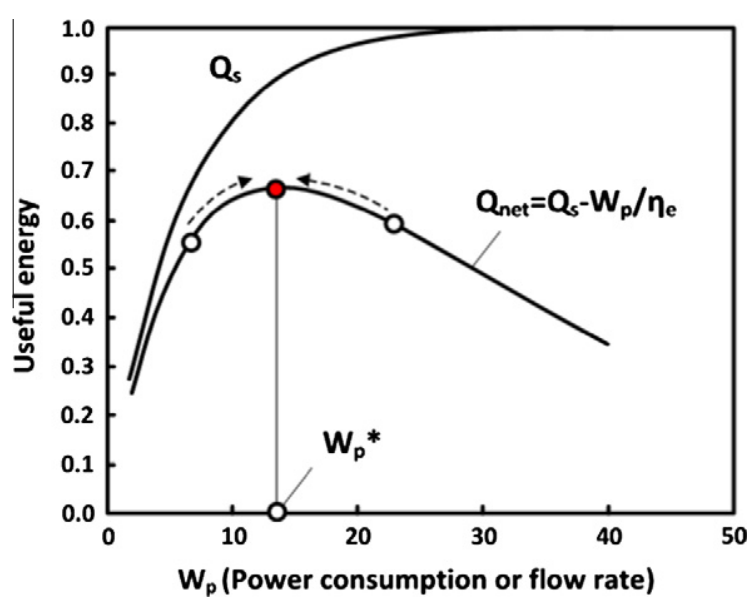

Fig. 3. Concept of $Q_{s}$ and $Q_{n e t}$ vs. pumping power.

the collector inlet and outlet temperatures, respectively. There seems exists an optimal flow rate at which the net heat collection is maximum and the pumping power is minimized. The definition of net energy gain $Q_{n e t}$ is similar to the cost function of Kovarik and Lesse (1976) or the exergy concept (Bejan and Schultz, 1982) and may have a maximum value as shown in Fig. 3. Since $Q_{\text {net }}$ varies with solar radiation and ambient conditions (wind and temperature), there may not be an optimal value of $Q_{n e t}$ all the time. The feasibility of using $Q_{n e t}$ as the cost function in the MPPT of solar heating system needs to be verified experimentally.

A steady or quasi-steady state data were screened out from field test data at different mass flow rates to determine the instantaneous $Q_{s}$ and $Q_{n e t}$ at fixed solar irradiation $I_{T}$. Fig. 4 shows that at a fixed solar radiation intensity
$I_{T}=880 \mathrm{~W} / \mathrm{m}^{2}$, there exists an optimal flow rate at which the net heat gain $Q_{\text {net }}$ is maximum and denoted as $Q_{\max }$. $Q_{\max }(14.9 \mathrm{~kW})$ is at flow rate $22 \mathrm{~kg} / \mathrm{min}(0.37 \mathrm{~kg} / \mathrm{s})$. The measured pumping power is $113 \mathrm{~W}$ at a reduction of $73 \%$ pumping power and the total heat energy collected $Q_{s}$ is $15.2 \mathrm{~kW}$. The experiment was carried out from 11:00 AM to 13:00 PM on a clear day, thus, the solar radiation intensity is approximately constant.

To evaluate the performance of solar heating system, the coefficient of performance (COP) is defined as:

$\mathrm{COP}=\frac{Q_{s}}{W_{p}}$

The power consumption of pump $W_{p}(\mathrm{~W})$ was determined experimentally at different mass flow rate $\dot{m}(\mathrm{~kg} / \mathrm{s})$ and an empirical relation was derived:

$W_{p}=2505.6 \dot{m}^{3}-1124.6 \dot{m}^{2}+393.5 \dot{m}$

It is seen that a very high electrical COP of the solar heating system $\left(Q_{s} / W_{p}=134.5\right)$ is obtained at the optimal point.

\section{Design of MPPT control system}

\subsection{Feedback structure of MPPT}

One of the feedback structures for MPPT in solar heating system can be the same as the popular step-up/stepdown control used in the MPPT of solar PV systems (Salas et al., 2006), as shown in Fig. 5. The cost function at time instant $i$, denoted $F_{i}$, is fed back to the one-step delay filter to determine $F_{i-1}$. The comparator compares $F_{i}$ and $F_{i-1}$ 


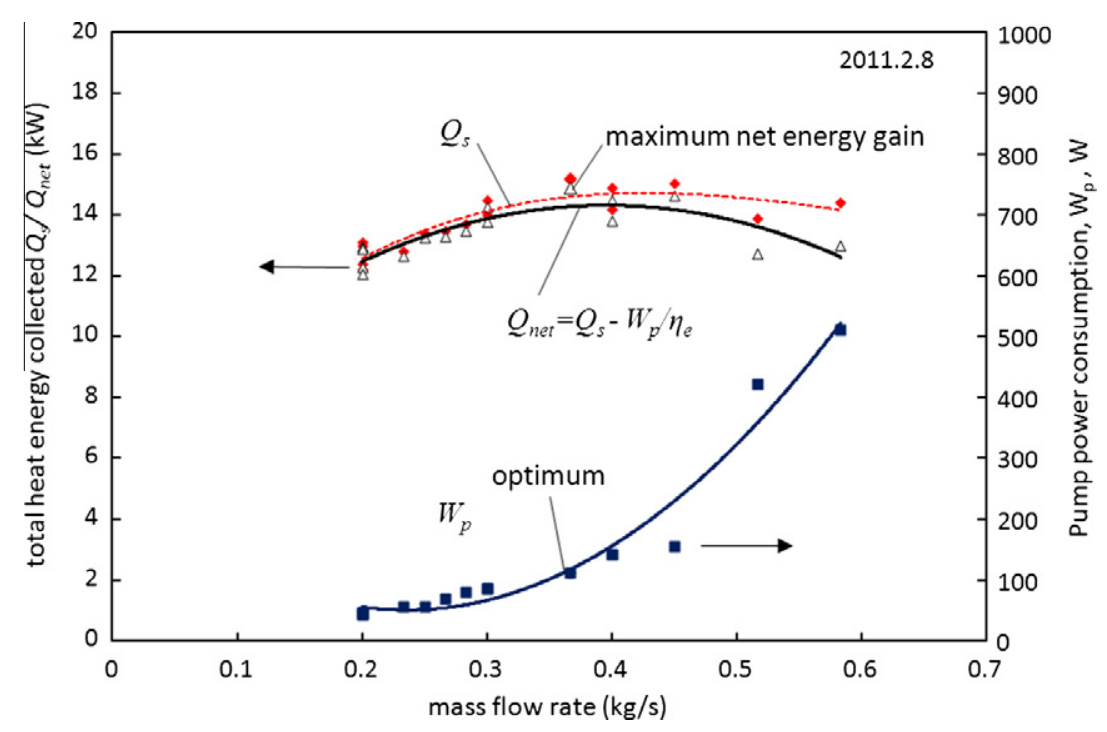

Fig. 4. Steady performance of a solar heating system at $I_{T}=880 \mathrm{~W} / \mathrm{m}^{2}$.

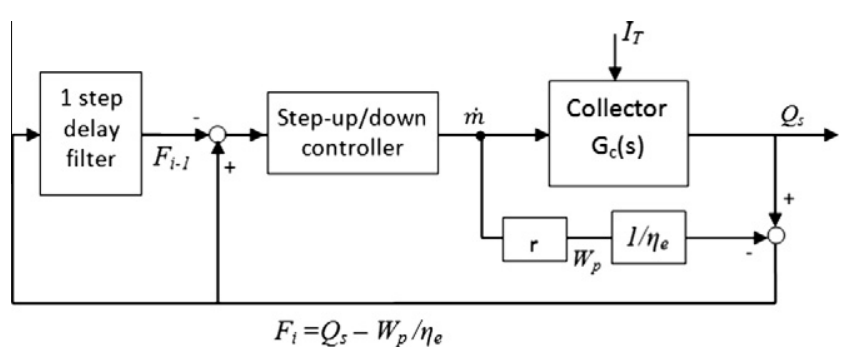

Fig. 5. Step-up/step-down control in MPPT.

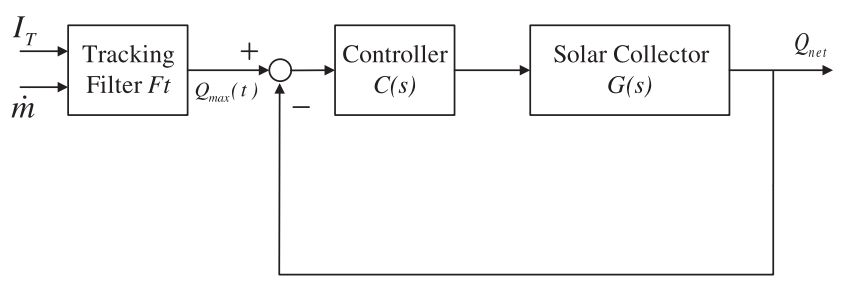

Fig. 6. Basic configuration of optimal tracking control system.

and outputs a signal $F_{i}-F_{i-1}$ to the controller. The stepup/down controller then outputs a control signal to regulate the flow rate up or down according to the sign of the change $F_{i}-F_{i-1}$. Since the electrical response to the variation of solar radiation is fast in PV system due to photovoltaic phenomenon, this kind of control algorithm may work very well with typical triggering such as perturbation and observation (P\&O) (Salas et al., 2006; Enrique et al., 2010). However, for solar heating system, the thermal response of solar collector is relatively slow due to larger thermal mass in the solar-thermal process. The step-up/ down controller cannot work very well when solar radiation is varying. A tracking control system is thus proposed in the present study.
Fig. 6 shows the basic configuration of the tracking control system for maximum $Q_{\text {net }}$ (i.e. $Q_{\max }$ ) in the solar heating system. The tracking filter $F t$ is used to determine the instantaneous maximum value of $Q_{\text {net }}$ (i.e. $Q_{\max }$ ) as the tracking target, from the calculation based on a known dynamic model. The tracking controller $C(s)$ can then be designed to track the time-variant $Q_{\max }$.

\subsection{Derivation of time-variant tracking target $Q_{\max }$}

Since the performance of solar heating system varies with solar radiation intensity $I_{T}$ and the mass flow rate $\dot{m}, Q_{\max }$ is time-variant and can be determined at any time instant if the thermal analytical model of the solar heating system is known.

\subsubsection{Derivation of system dynamic model of solar heating system}

The tracking filter $F t$ is used to determine the instantaneous MPP of the solar heating system. The thermal performance of solar collector is a dynamic behavior due to the variation of environment including solar radiation, wind speed, etc. A first-order thermal model was first derived by Close (1967) using lumped concept, called "lumped model", and then utilized and corrected by Klein et al. (1974) considering the fluid temperature variation with position, called "one-node capacitance model". This model was further modified by Wang et al. (1987), called "first-order model", and experimentally verified by Huang and Hsieh (1990) who showed that the first-order model can fit the experimental results reasonably well. Hence, we adopted the first-order model (Wang et al., 1987) in the present study:

$\tau_{s} \frac{d q_{s}}{d t}+q_{s}=F_{R}(\tau \alpha) I_{T}-F_{R} U_{L}\left(T_{i}-T_{a}\right)$ 

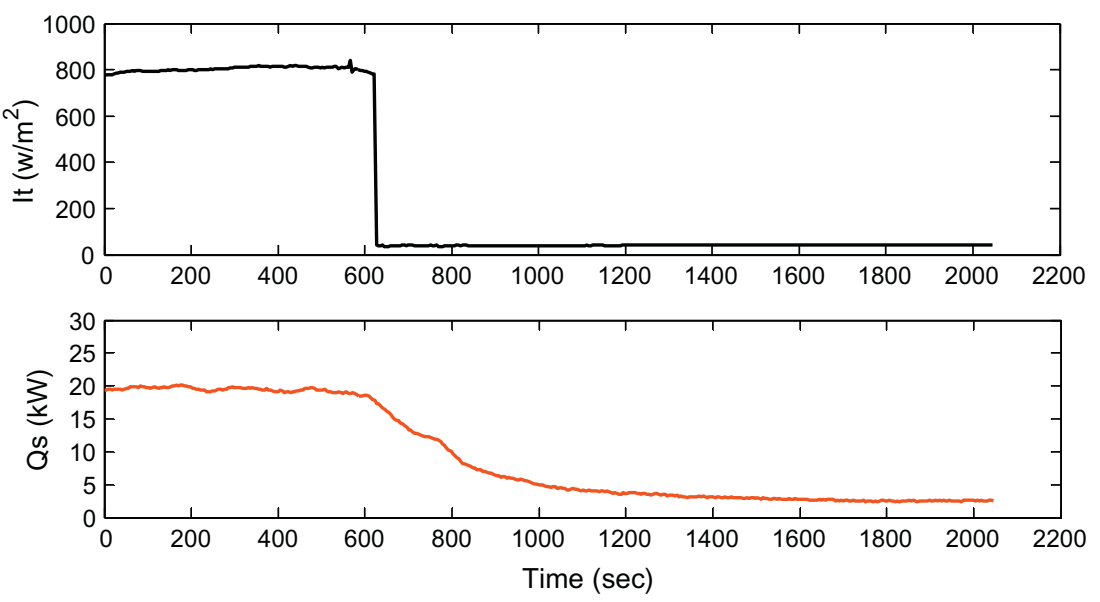

Fig. 7. Step response test of the solar heating system.

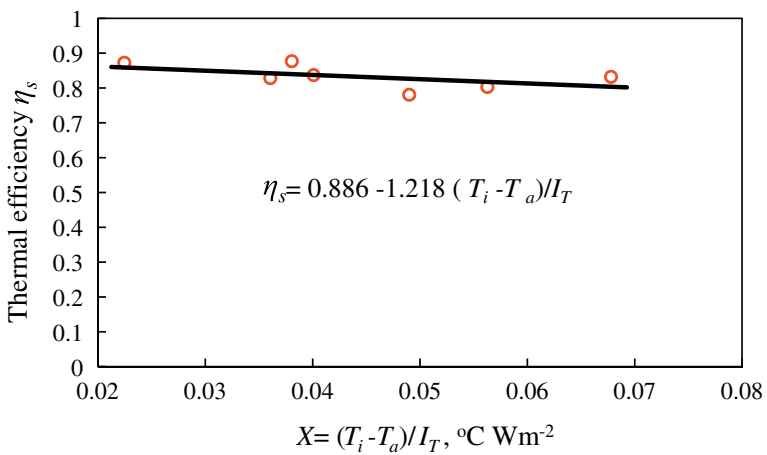

Fig. 8. Thermal efficiency test results of solar collector banks at $\dot{m}=0.64 \mathrm{~kg} / \mathrm{s}$.

where $q_{\mathrm{s}}=Q_{s} / A_{c}$ and $\tau_{s}$ is the time constant of the solar heating system which represents the time to reach $63.2 \%$ of the step change due to a step input to the system. $F_{R}(\tau \alpha)$ and $F_{R} U_{L}$ are the collector parameters defined as the following steady-state thermal efficiency relation:

$\eta_{s}=F_{R}(\tau \alpha)-\frac{F_{R} U_{L}\left(T_{i}-T_{a}\right)}{I_{T}}$

The time constant $\tau_{s}$ was determined from a step response test of the solar system (Fig. 7) by quickly shading all the solar collectors when the solar heating system is

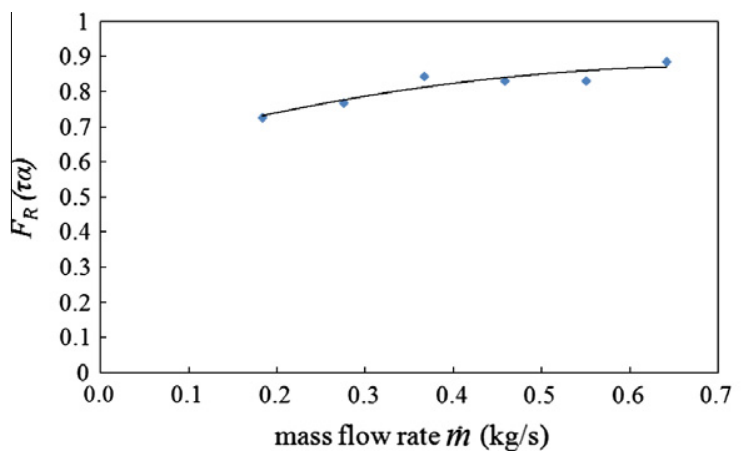

running at a steady state with approximately constant solar radiation, circulation flow rate, and inlet temperature. The experiment was carried out during the noon (11:00-13:00) with stable solar radiation. The test result shows that $\tau_{s}=237 \mathrm{~s}$ from fitting the test result to the first-order model, Eq. (4).

The two parameters $F_{R}(\tau \alpha)$ and $F_{R} U_{L}$ are determined by fitting the steady-state data collected from field tests to the relation, Eq. (5). Fig. 8 shows the result for $\dot{m}=0.64 \mathrm{~kg} / \mathrm{s}$. Repeating the experiments at different mass flow rate $\dot{m}$, we obtain Fig. 9.

The following correlations for steady-state performance were derived:

$F_{R}(\tau \alpha)=-0.51 \dot{m}^{2}+0.72 \dot{m}+0.62, \quad$ dimensionless

$F_{R} U_{L}=-2.97 \dot{m}^{2}+3.9 \dot{m}-0.14, \quad \mathrm{Wm}^{-2} \mathrm{~K}^{-1}$

The above Eq. (6) and (7) are derived for the solar system with total collector area $25.92 \mathrm{~m}^{2}$. The unit of mass flowrate $\dot{m}$ is in $\mathrm{kg} / \mathrm{s}$.

Eqs. 4, 6, and 7 can be used to determine $Q_{\max }$ at $\dot{m}=\dot{m}_{\text {opt }}$ for solar radiation intensity $I_{T}$ at any time instant.

\subsubsection{Determination of $Q_{\max }$}

The maximum $Q_{\text {net }}$ (i.e. $Q_{\max }$ ) can be determined by taking derivative of $Q_{\text {net }}$ with respect to mass flow rate $\dot{m}$, that is:

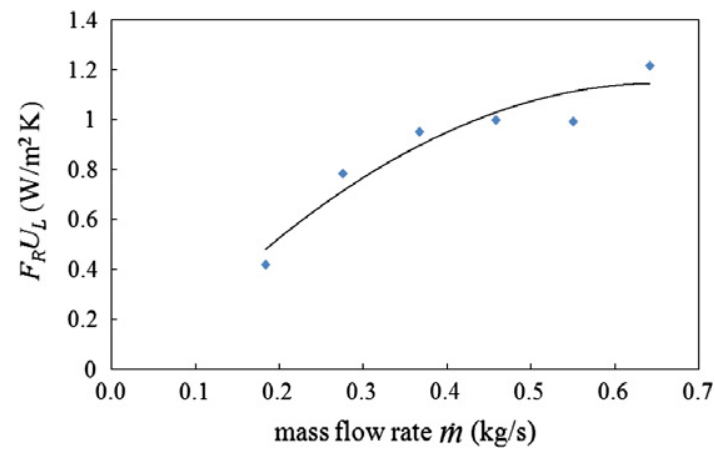

Fig. 9. Variation of $F_{R}(\tau \alpha)$ and $F_{R} U_{L}$ with mass flow rate $\dot{m}$. 
$Q_{\max }=\left.\frac{\partial Q_{n e t}}{\partial \dot{m}}\right|_{\dot{m}=\dot{m}_{o p t}}=\frac{\partial}{\partial \dot{m}}\left[Q_{s}-\frac{W_{p}}{\eta_{s}}\right]_{\dot{m}=\dot{m}_{o p t}}=0$

To determine the $Q_{\max }$ at any time instant, Eq. (4) is first written in discrete form at time interval $\Delta t_{s}$ :

$\tau_{s} \frac{q_{s, j+1}-q_{s, j}}{\Delta t_{s}}+q_{s, j}=\left[F_{R}(\tau \alpha)\right]_{j} I_{T, j}-\left[F_{R} U_{L}\right]_{j}\left(T_{i, j}-T_{a, j}\right)$ is:

The total net energy collection rate at time instant $j+1$

$$
\begin{aligned}
Q_{n e t, j+1}= & Q_{s, j+1}-\frac{W_{p}}{\eta_{e}} \\
= & \frac{\frac{\tau_{s}}{\Delta t_{s}} q_{s, j}+\left[F_{R}(\tau \alpha)\right]_{j} I_{T, j}-\left[F_{R} U_{L}\right]_{j}\left(T_{i, j}-T_{a, j}\right)}{\frac{\tau_{s}}{\Delta t_{s}}+1} A_{c}-\frac{W_{p}}{\eta_{e}} \\
= & \frac{A_{c}}{\frac{\tau_{s}}{\Delta t_{s}}+1}\left[\frac{\tau_{s}}{\Delta t_{s}} q_{s, j}+\left(-0.51 \dot{m}_{j}^{2}+0.72 \dot{m}_{j}+0.62\right) I_{T, j}\right. \\
& \left.-\left(-2.97 \dot{m}_{j}^{2}+3.9 \dot{m}_{j}-0.14\right)\left(T_{i, j}-T_{a, j}\right)\right] \\
& -\frac{2505.6 \dot{m}_{j}^{3}-1124.6 \dot{m}_{j}^{2}+393.5 \dot{m}_{j}}{\eta_{e}}
\end{aligned}
$$

It is seen from Eq. (10) that there exists a maximum value of $Q_{n e t, j+1}$ at which $\dot{m}_{j}=\dot{m}_{o p t}$ for a given $I_{T, j}, T_{i, j}$ and $T_{a, j}$ at time instant $j$. Hence, we can determine the optimal mass flow rate by taking partial derivative with respect to mass flow rate $\dot{m}_{j}$ and setting it equal to zero at which $\dot{m}_{j}=\dot{m}_{\text {opt }}$. We then obtain:

$\dot{m}_{\text {opt }}=\frac{-\beta+\sqrt{\beta^{2}-4 \varepsilon \gamma}}{2 \varepsilon}$

where

$\varepsilon=\frac{7516.8}{\eta_{e}}$

$\beta=\left[1.02 I_{T, j}-5.84\left(T_{i, j}-T_{a, j}\right)\right] \frac{A_{c}}{\frac{\tau_{s}}{\Delta t_{s}}+1}-\frac{2328.5}{\eta_{e}}$

$\gamma=-\left[0.72 I_{T, j}-3.9\left(T_{i, j}-T_{a, j}\right)\right] \frac{A_{c}}{\frac{\tau_{s}}{\Delta t_{s}}+1}+\frac{393.5}{\eta_{e}}$

$Q_{\max }$ is then determined by the following equation.

$$
\begin{aligned}
Q_{\max }= & Q_{s, j+1}\left(\dot{m}_{\text {opt }}\right)-\frac{W_{p}\left(\dot{m}_{\text {opt }}\right)}{\eta_{e}} \\
= & \frac{A_{c}}{\frac{\tau_{s}}{\Delta t_{s}}+1}\left[\frac{\tau_{s}}{\Delta t_{s}} q_{s, j}+\left(-0.51 \dot{m}_{\text {opt }}^{2}+0.72 \dot{m}_{\text {opt }}+0.62\right) I_{T, j}\right. \\
& \left.-\left(-2.97 \dot{m}_{\text {opt }}^{2}+3.9 \dot{m}_{\text {opt }}-0.14\right)\left(T_{i, j}-T_{a, j}\right)\right] \\
& -\frac{2505.6 \dot{m}_{\text {opt }}^{3}-1124.6 \dot{m}_{\text {opt }}^{2}+393.5 \dot{m}_{\text {opt }}}{\eta_{e}}
\end{aligned}
$$

Eq. (12) associated with Eq. (11) will be used to calculate $Q_{\max }$ at time $j+1$ as the tracking target in the MPPT control system. $I_{T, j}, T_{i, j}$ and $T_{a, j}$ are assumed constant during the time step $\Delta t_{s} . I_{T, j}$ can be taken as the filtered value using a low-pass filter $F i$.

\subsection{Design of MPPT}

\subsubsection{Identification of system dynamic model of solar heating system}

For tracking control system design, the system dynamic model of solar heating system has to be known. The dynamic behavior of solar collector system is nonlinear. A linear perturbation model was then derived from Eqs. 4, 6, 7 using the following definitions:

$\tilde{q}_{s}(t)=q_{s}(t)-\bar{q}_{s}$

$\tilde{\dot{m}}(t)=\dot{m}(t)-\overline{\dot{m}}$

$\widetilde{I}_{T}(t)=I_{T}(t)-\bar{I}_{T}$

$\widetilde{T}_{a}(t)=T_{a}(t)-\bar{T}_{a}$

$\widetilde{T}_{i}(t)=T_{i}(t)-\bar{T}_{i}$

$\Delta T_{i a}(t)=T_{i}(t)-T_{a}$

$\Delta \tilde{T}_{i a}(t)=\left[T_{i}(t)-\bar{T}_{i}\right]-\left[T_{a}(t)-\bar{T}_{a}\right]=\Delta T_{i a}(t)-\Delta \bar{T}_{i a}$

where $\bar{q}_{s}$ is the steady state of $q_{s}, \overline{\dot{m}}$ is the steady state of $\dot{m}$; $\bar{T}_{i}$ is the steady state of $T_{i} ; \bar{I}_{T}$ is the steady state of $I_{T}$. The linearly-perturbed dynamic system is assumed to operate near the steady state with small variation.

Assuming that the variations of collector inlet temperature $T_{i}$ and ambient temperature $T_{a}$ are small during the tracking control period, we have $\Delta \widetilde{T}_{i a}(t)=0$. Substituting the linear perturbation relation into Eq. (4) and neglecting the second-order terms, we obtain the following linear perturbation equation:

$$
\begin{aligned}
237 \dot{\tilde{q}}_{s}+\tilde{q}_{s}= & {\left[(-1.02 \overline{\dot{m}}+0.72) \bar{I}_{T}\right] \tilde{\dot{m}} } \\
& +\left(-0.51 \overline{\dot{m}}^{2}+0.72 \overline{\dot{m}}+0.62\right) \widetilde{I}_{T}
\end{aligned}
$$

Taking Laplace transform of Eq. (14), we obtain the following transfer-function model, whose block diagram is shown in Fig. 10:

$$
\begin{aligned}
G_{m}(s) & =\frac{\tilde{q}_{s}(s)}{\tilde{\dot{m}}(s)}=\frac{(-1.02 \overline{\dot{m}}+0.72) \bar{I}_{T}}{237 s+1} \\
G_{I}(s) & =\frac{\tilde{q}_{s}(s)}{\widetilde{I}_{T}(s)}=\frac{-0.51 \overline{\dot{m}}^{2}+0.72 \overline{\dot{m}}+0.62}{237 s+1}
\end{aligned}
$$

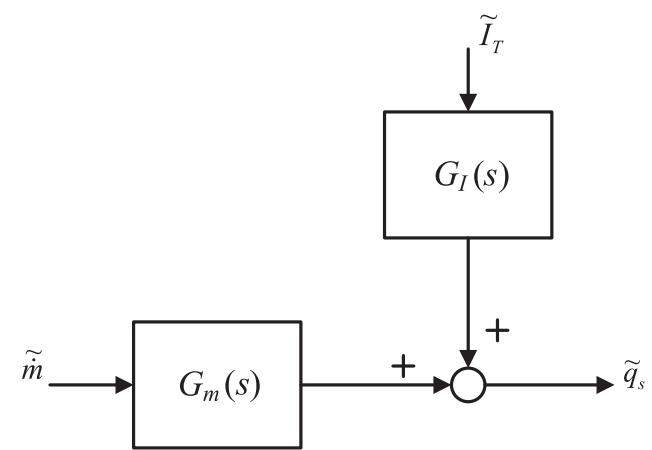

Fig. 10. System dynamic model of solar heating system. 


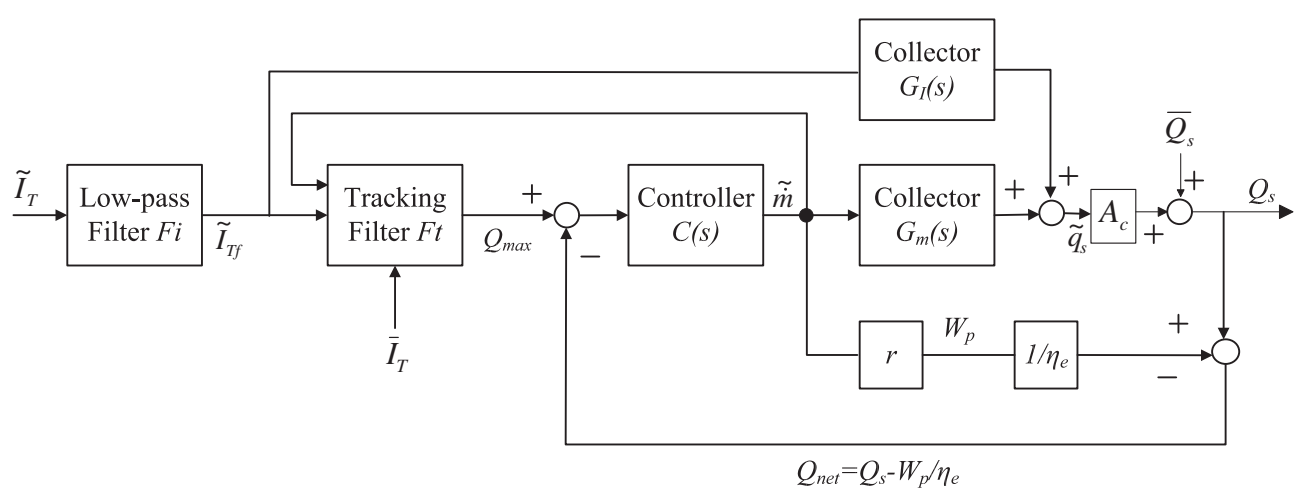

Fig. 11. MPPT feedback control system.

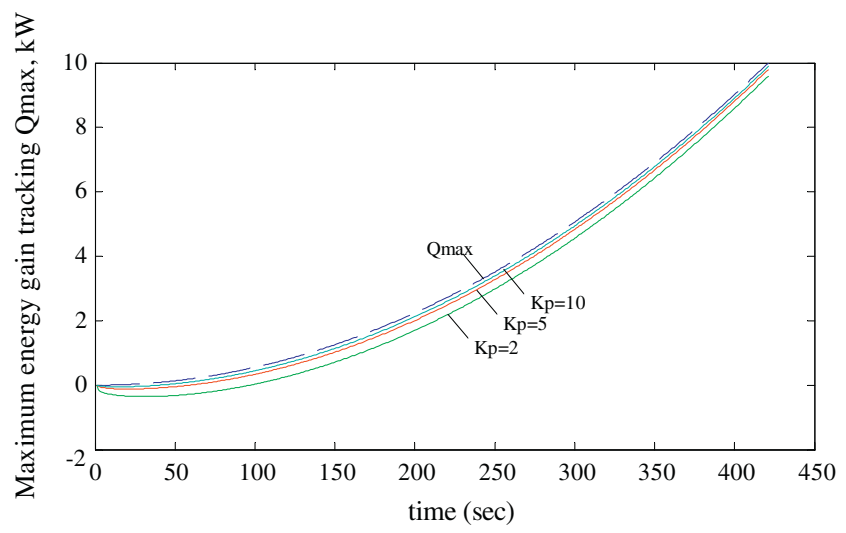

Fig. 12. Tracking system simulation P-control only.

It is seen that the system dynamic behavior of solar thermal system is first-order.

\subsubsection{Design of MPPT feedback tracking control system}

The system dynamic model derived above can be used in the design of MPPT feedback control system as shown in Fig. 11. Since the system dynamic response of the solar collector has a low-pass property (with time constant $\tau_{s}=237 \mathrm{~s}$ ), a low-pass filter $F i$ can be used to filter out the fast variation of solar radiation pattern.

Given the variation of cost function $Q_{\max }(t)$, the tracking performance of the control system can be simulated using Matlab/Simulink and the controller design $C(s)$ can be made. The PI control (Proportional-Integral) was chosen as the controller, the following equation:

$C(s)=K_{p}+\frac{1}{T_{I} S}$

In the system simulation, the control target $Q_{\max }(t)$ was assumed a quadratic function from 0 to $10 \mathrm{~kW}$ in $420 \mathrm{~s}$. Fig. 12 shows that the tracking error for P-control only is small and not sensitive for $K_{p}>10$. Therefore, further simulation was carried out at $K_{p}=10$ to find the suitable $T_{I}$ for integral control. Fig. 13 shows that the tracking error for $T_{I}=5$ performs satisfactory. The PI controller became:

$C(s)=10+\frac{1}{5 s}$

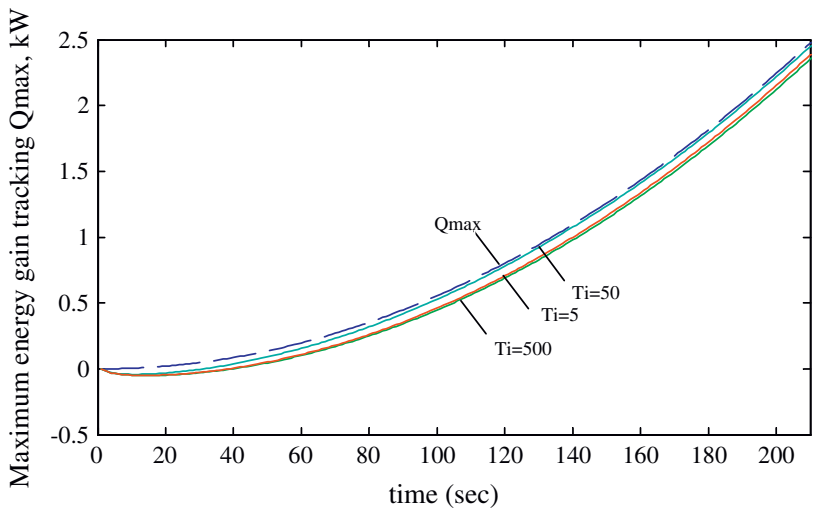

Fig. 13. Tracking system simulation at different $T_{I}\left(K_{p}=10\right)$.

\section{Test of solar heating system with MPPT control}

The solar heating system was tested using the above MPPT control system which was implemented on a PIC16F877A microprocessor-based controller. The whole control system is as shown in Fig. 2. The whole control system consists of a PC, a MPPT controller, some measuring devices for mass flow rate, power input of pump, temperatures, solar radiation intensity, and a RS232 interface for communication between them. A 8-bit DAC0800 was used to convert the digital control signal into analogue actuating signal to the inverter of the pump to change the rotational speed as well as the mass flow rate. The tracking target $Q_{\max }(t)$ was calculated using Eq. (12) and the measurements at each time step $\Delta t_{s}$ was set at $6 \mathrm{~s}$.

The test results of 2011/8/10 (cloudy weather) as shown in Fig. 14 and Table 1 show that the MPPT control works well. During the MPPT control period 11:37-13:03, the solar radiation varies between 237 and $961 \mathrm{~W} / \mathrm{m}^{2}$ (average 487); the mass flow rate varies between 10 and $24 \mathrm{~kg} / \mathrm{min}$ with pumping power $30-128 \mathrm{~W}$ (average $77 \mathrm{~W}$ ); collector exit temperature between 85.2 and $96.5^{\circ} \mathrm{C}$ (average 90.3); $Q_{n e t}$ between 2.92 and $18.8 \mathrm{~kW}$ (average 8.62); $Q_{\text {net }}$ tracking error between 0 and $4.02 \mathrm{~kW}$ (average 1.02); and the COP varies between 62 and 208 (average 120). It is seen that $\mathrm{COP}$ increases with increasing solar radiation $I_{T}$, with about one minute delay. 


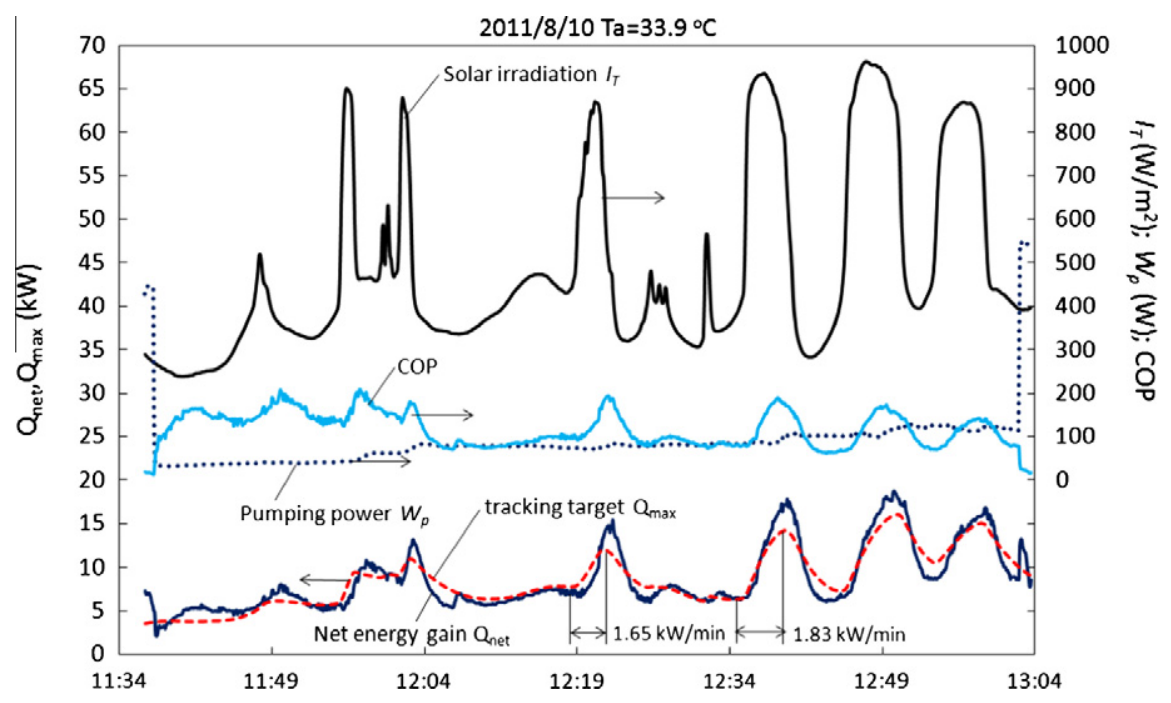

Fig. 14. Test result of MPPT (2011/8/10).

Table 1

Tracking performance of MPPT control.

\begin{tabular}{|c|c|c|c|c|c|c|c|c|c|c|c|c|}
\hline & \multirow[t]{2}{*}{$T_{a}\left({ }^{\circ} \mathrm{C}\right)$} & \multirow[t]{2}{*}{$T_{i}\left({ }^{\circ} \mathrm{C}\right)$} & \multirow[t]{2}{*}{$T_{e}\left({ }^{\circ} \mathrm{C}\right)$} & \multirow{2}{*}{$\begin{array}{l}I_{T} \\
\left(\mathrm{~W} / \mathrm{m}^{2}\right)\end{array}$} & \multirow{2}{*}{$\begin{array}{l}\text { Flow rate } \\
(\mathrm{kg} / \mathrm{min})\end{array}$} & \multirow{2}{*}{$\begin{array}{l}W_{p} \\
(\mathrm{~W})\end{array}$} & \multirow[t]{2}{*}{$\mathrm{COP}$} & \multirow{2}{*}{$\begin{array}{l}Q_{n e t} \\
(\mathrm{~kW})\end{array}$} & \multirow{2}{*}{$\begin{array}{l}\text { Target } \\
Q_{\max }(\mathrm{kW})\end{array}$} & \multicolumn{3}{|c|}{ Tracking error $(\mathrm{kW})$} \\
\hline & & & & & & & & & & $Q_{\text {net }}-Q_{\max }$ & $a b s\left(Q_{n e t}-Q_{\max }\right)$ & $a b s$ error $(\%)$ \\
\hline \multicolumn{13}{|c|}{$2011 / 8 / 1011: 37-13: 03$} \\
\hline Max & 36.7 & 90.5 & 96.5 & 961 & 24.0 & 128 & 208 & 18.8 & 16.0 & 4.02 & 4.02 & 41.4 \\
\hline Average & 33.9 & 83.2 & 90.3 & 487 & 17.6 & 77 & 120 & 8.62 & 8.62 & -0.00 & 1.02 & 12.5 \\
\hline \multicolumn{13}{|c|}{$2011 / 8 / 1110: 38-12: 09$} \\
\hline Average & 34.4 & 87.8 & 92.4 & 517 & 20.0 & 91 & 112 & 10.1 & 9.8 & 0.3 & 0.7 & 5.8 \\
\hline
\end{tabular}

The larger tracking error at the periods of sudden change of solar radiation as shown in Fig. 15 is due to the tracking system response problem and the prediction error of tracking target $Q_{\max }(t)$ using the tracking filter, Eq. (12).
The MPPT controller was designed using a quadratic time function of tracking target $Q_{\max }(t)$ from 0 to $10 \mathrm{~kW}$ in $420 \mathrm{~s}$, at an average rate of change $1.43 \mathrm{~kW} / \mathrm{min}$. This is very close to the real test result: the rate of change of $Q_{\max }(t)$ was about $1.83 \mathrm{~kW} / \mathrm{min}$ at $12: 35$ and $1.65 \mathrm{~kW} /$

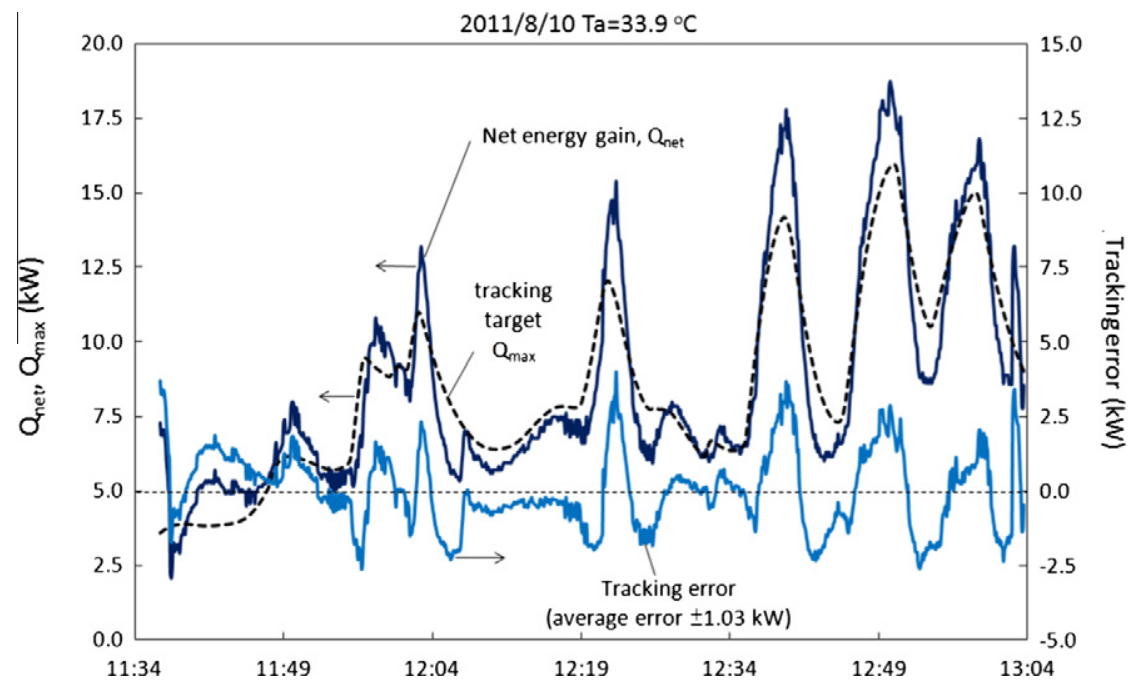

Fig. 15. Tracking error of MPPT (2011/8/10). 


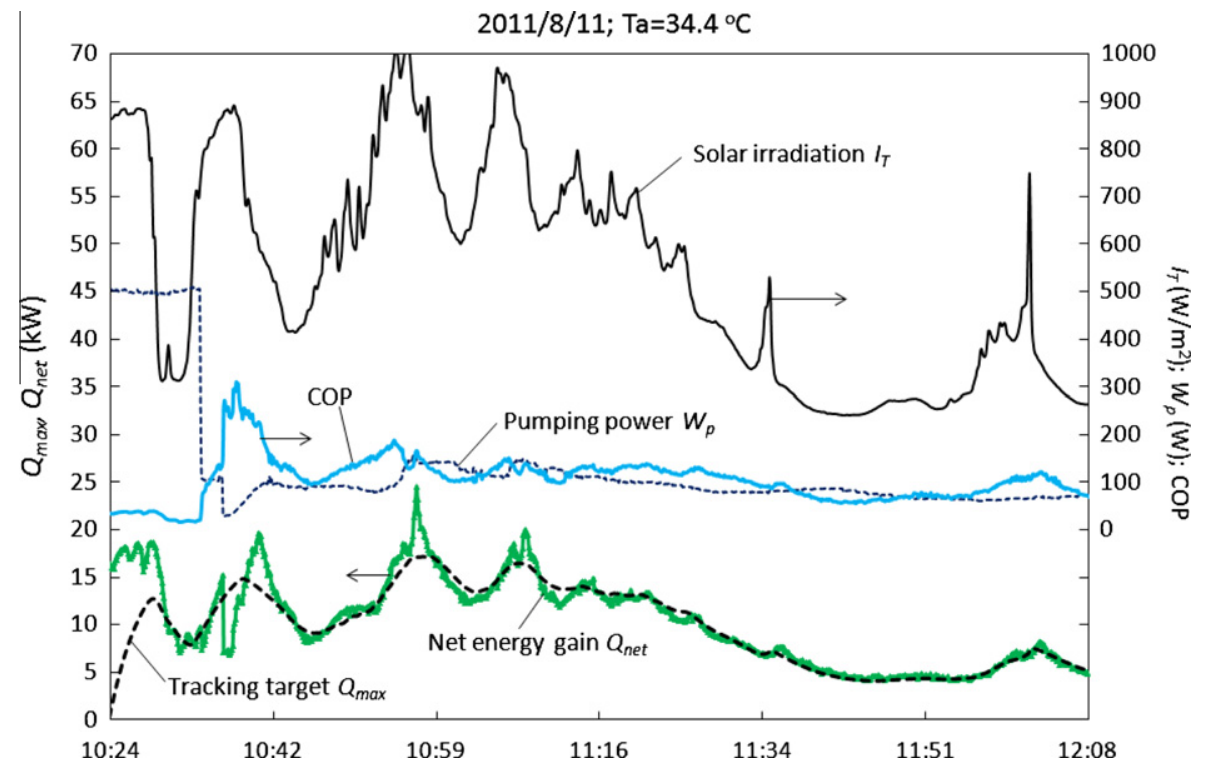

Fig. 16. Test result of MPPT (2011/8/11).

min at 12:19, both are close to the assumed quadratic target function of $Q_{\max }(t)$ in the MPPT controller design. The prediction error of tracking target $Q_{\max }(t)$ using the tracking filter, Eq. (12), may come from the dynamic effect of fast variation of solar irradiation $I_{T}$.

The average tracking error is $\pm 1.02 \mathrm{~kW}$, about $12 \%$ with respect to the average $Q_{n e t}$ which is acceptable. The pumping power was reduced tremendous from $550 \mathrm{~W}$ to 30 $128 \mathrm{~W}$ (average $77 \mathrm{~W}$ ).

Another cloudy-day test $(2011 / 8 / 11)$ shows similar phenomena as shown in Fig. 16. During the MPPT control period 10:38-12:09, the solar radiation varies between 242 and $1037 \mathrm{~W} / \mathrm{m}^{2}$ (average 517); the mass flowrate varies between 11 and $25 \mathrm{~kg} / \mathrm{min}$ with pumping power $39-155 \mathrm{~W}$ (average $91 \mathrm{~W}$ ); collector exit temperature between 82.6 and $102.7^{\circ} \mathrm{C}$ (average 92.4); $Q_{n e t}$ between 4.2 and $24.5 \mathrm{~kW}$ (average 10.1); $Q_{\text {net }}$ tracking error (abs) between 0 and $7.5 \mathrm{~kW}$ (average 0.7); and the COP varies between 57 and 309 (average 112). The error in tracking the target $Q_{\max }(t)$ is greatly reduced in $2011 / 8 / 11$, especially in the latter part of the test after 11:16, as shown in Fig. 17. This is due to the lower solar radiation fluctuation. The weather of 2011/8/11 was better than 2011/8/10.

We summarized the averaged results of some typical tests at the periods under MPPT control in summer, as shown in Table 2 . It is seen that the highest average $Q_{\text {net }}$ was $14.1 \mathrm{~kW}$ with $\mathrm{COP}=104$ in a clear day $(2011 / 6 / 23)$ with average $I_{T}=746 \mathrm{~W} / \mathrm{m}^{2}$ and average collector inlet

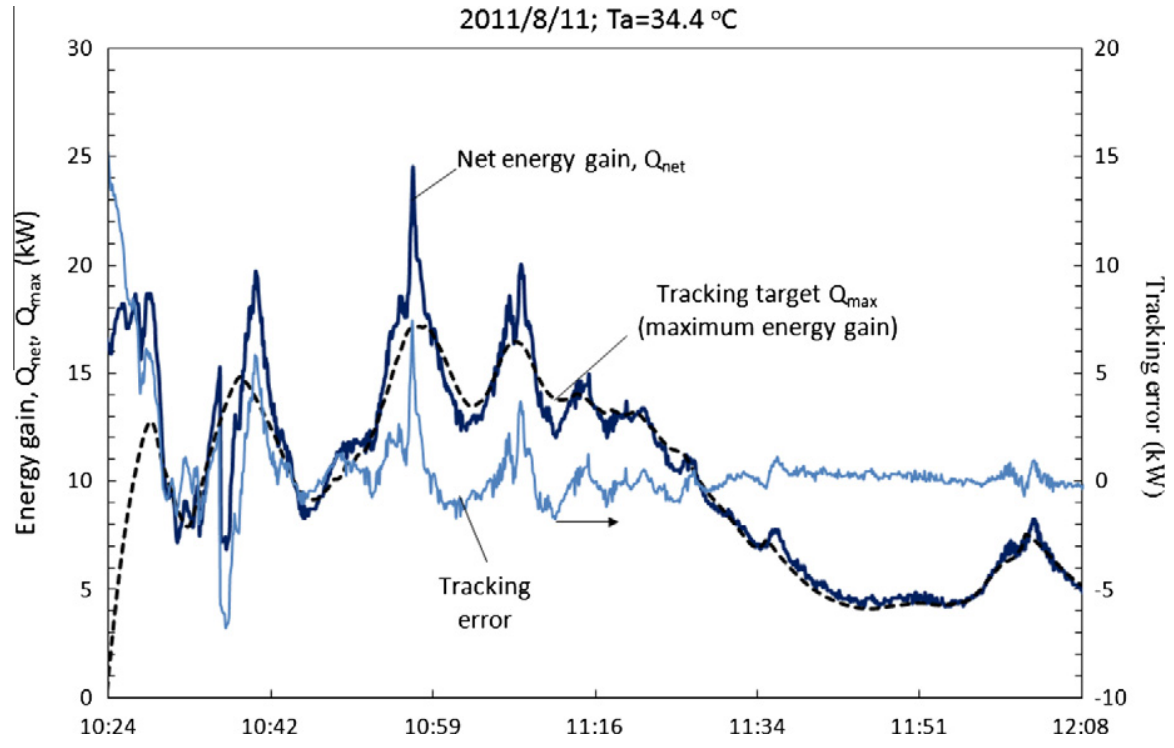

Fig. 17. Tracking error of MPPT (2011/8/11). 
Table 2

Averaged results at the periods under MPPT control.

\begin{tabular}{|c|c|c|c|c|c|c|c|c|c|}
\hline Date & Test time h:min & $T_{a}\left({ }^{\circ} \mathrm{C}\right)$ & $T_{i}\left({ }^{\circ} \mathrm{C}\right)$ & $I_{T}\left(\mathrm{~W} / \mathrm{m}^{2}\right)$ & Flow rate $\left(\mathrm{kg} / \mathrm{min} / \mathrm{m}^{2}\right)$ & $Q_{\text {net }}(\mathrm{kW})$ & $W_{p}(\mathrm{~W})$ & $\mathrm{COP}$ & $A_{c}\left(\mathrm{~m}^{2}\right)$ \\
\hline $2011 / 6 / 22$ & $2: 40$ & 35.9 & 89.8 & 570 & 0.70 & 10.5 & 101 & 111 & 25.9 \\
\hline $2011 / 6 / 23$ & $5: 13$ & 33.4 & 92.6 & 746 & 0.84 & 14.1 & 140 & 104 & 25.9 \\
\hline $2011 / 8 / 08$ & $1: 14$ & 35.2 & 86.7 & 684 & 0.88 & 12.4 & 130 & 99 & 25.9 \\
\hline 2011/8/11 & $1: 31$ & 34.4 & 87.8 & 517 & 0.77 & 10.1 & 91 & 112 & 25.9 \\
\hline
\end{tabular}

temperature $T_{i}=92.6{ }^{\circ} \mathrm{C}$. The test time is the longest, with $5 \mathrm{~h}$ and $13 \mathrm{~min}$ and the average pumping power is also the highest $(140 \mathrm{~W})$.

The measured lowest average $Q_{\text {net }}$ was $8.62 \mathrm{~kW}$ with $\mathrm{COP}=120$ in a cloudy day $(2011 / 8 / 10)$ with average $I_{T}=487 \mathrm{~W} / \mathrm{m}^{2}$ and average collector inlet temperature $T_{i}=83.2{ }^{\circ} \mathrm{C}$. The average pumping power is also the lowest $(77 \mathrm{~W})$.

It is seen that the average mass flow rate of the specific test periods in five different days is between 18.1 and $22.9 \mathrm{~kg} / \mathrm{min}$ with average pumping power between 77 and $140 \mathrm{~W}$, which is greatly reduced as compared to the standard flow rate at $31 \mathrm{~kg} / \mathrm{min}\left(0.02 \mathrm{~kg} / \mathrm{s} \mathrm{m}^{2}\right)$ at $450 \mathrm{~W}$ pumping power.

\section{Conclusion}

The present study developed a maximum-power point tracking control (MPPT) technology for solar heating system to minimize the pumping power consumption at an optimal heat collection. The net solar energy gain $Q_{\text {net }}$ $\left(=Q_{s}-W_{p} / \eta_{e}\right)$ was found to be the cost function with maximum point from the analysis of steady-test results. The feedback tracking control system was developed to track the optimal $Q_{\text {net }}$ (denoted $Q_{\max }$ ). A tracking filter which was derived from the thermal analytical model of the solar heating system was used to determine the instantaneous tracking target $Q_{\max }(t)$ to take into account the effect of time variation of solar radiation and temperatures. The system transfer-function model of solar heating system was also derived experimentally using a step response test. This model was then used in the design of tracking feedback control system for a given time-variant tracking target $Q_{\max }(t)$. The PI controller was designed for a tracking target $Q_{\max }(t)$ with a quadratic time function. The whole MPPT control system was implemented using a microprocessor-based controller, a PC, and measuring devices, etc. to control the mass flow rate of the solar heating system. The test results show a good tracking performance with small tracking errors.
It is seen that the average mass flow rate for the specific test periods in five different days is between 18.1 and $22.9 \mathrm{~kg} / \mathrm{min}$ with average pumping power between 77 and $140 \mathrm{~W}$, which is greatly reduced as compared to the standard flow rate at $31 \mathrm{~kg} / \mathrm{min}\left(0.02 \mathrm{~kg} / \mathrm{s} \mathrm{m}^{2}\right)$ at pumping power $450 \mathrm{~W}$. The average net solar heat collected $Q_{\text {net }}$ is between 8.62 and $14.1 \mathrm{~kW}$ depending on weather condition. The MPPT control of solar heating system has been verified to be able to minimize the pumping energy consumption with optimal solar heat collection.

\section{Acknowledgement}

This publication is based on work supported by Award No. KUK-C1-014-12, made by King Abdullah University of Science and Technology (KAUST), Saudi Arabia.

\section{References}

Badescu, Viorel, 2007. Optimal control of flow in solar collectors for maximum exergy extraction. Int. J. Heat Mass Transfer 50 (21-22), 4311-4322.

Bejan, A., Schultz, W., 1982. Optimum flow-rate history for cooldown and energy storage processes. Int. J. Heat Mass Transfer 25 (8), 1087-1092.

Close, D.J., 1967. A design approach for solar processes. Sol. Energy 11 (1967), 112-122.

De Winter, F., 1992. Comments on optimum flow rates in solar water heating systems with a counterflow exchanger. Sol. Energy 49 (6), $557-$ 558.

Enrique, J.M., Andu' jar, J.M., Boho'rquez, M.A., 2010. A reliable, fast and low cost maximum power point tracker for photovoltaic applications. Sol. Energy 84, 79-89.

Huang, B.J., Hsieh, S.W., 1990. An automation of collector testing and modification of ANSI/ASHRAE 93-1986 standard. Trans. ASME J. Sol. Energy Eng. 112, 257-267.

Klein, S.A., Duffie, J.A., Beckman, W.A., 1974. Transient considerations of flat-plate solar collectors. Trans. ASME J. Eng. Power 113, 109113.

Kovarik, M., Lesse, P.F., 1976. Optimal control of flow in low temperature solar heat collectors. Sol. Energy 18 (5), 431-435.

Salas, V., Olı'as, E., Barrado, A., La'zaro, A., 2006. Review of the maximum power point tracking algorithms for stand-alone photovoltaic systems. Sol. Energy Mater. Sol. Cells 90, 1555-1578.

Wang, X.A., Xu, X.F., Meng, X.Y., 1987. A filter method for transient testing of collector performance. Sol. Energy 38 (2), 125-134. 